\title{
A Microcosm of Chinese and American Cultures Reflected in the Movie Guasha Treatment
}

\author{
Yanchun Zhang \\ The Engineering \& Technical College \\ Chengdu University of Technology \\ Leshan, China
}

\begin{abstract}
Culture as the product of human social behavior is a unique phenomenon in which a wide range of culture elements are included. Standard of social moralities, life values and human customs can be transferred by means of film art. In this paper, it analyzes three typical culture differences reflected in the movie "Guasha Treatment" and put forward the idea that movie plays a positive role in promoting crosscultural communication in the era of globalization. Movie is not only a good way to transfer culture-loaded elements but also can be a reference for intercultural communication and the cultivation of people's cross-cultural awareness.
\end{abstract}

Keywords-Guasha treatment; culture difference; kinship; face; law

\section{INTRODUCTION}

Movie as a kind of modern art is a combination of literature, drama, music, dancing, photography, painting, writing and other kind of art. As it is the comprehensive practice of performance with a unique artistic feature. It reflects and represents life with film technology, creating the image on the screen. All aspects of social life are reproduced in TV programs or movie. With the continuous development of film or movie technology, the performance of film art is constantly improving, and the impact on social life is also increasingly widespread. It can enrich people's spiritual life, change the way of human life, and even affect human ideas

As for the term "culture", various definitions have been given. It is defined in Collins Cobuild Advanced Dictionary that "Culture consists of activities such as the arts and philosophy, which are considered to be important for the development of civilization and of people's minds. The culture of a particular organization or group consists of the habits of the people in it and the way the generally behave" (Collins Cobuild Advanced Dictionary, 2009: 263). And it is noted by $\mathrm{Xu}$ Lisheng in the book that, Intercultural Communication in English, "Sometimes we may even think about culture as commodities or products such as toys, food, films, videos, and music that are internationally exported and imported. In fact, culture is really a large and evasive concept, very difficult to define" (Xu Lisheng, 2009:30-40).

The movie is a form of culture, and the real life image is vividly reflected and shown to audiences through movies that cultural information such as social norms, moral norms, the outlook on life and life mode. People learn about cultural connotations of a certain area in a certain period by appreciating a film. What's more, with the development of imaging technology and the popularity of the film media, culture of a country of region can be spread rapidly worldwide, especially in the era of globalization. Therefore, the role of film in promoting intercultural communication can not to be underestimated.

In the book Communication between Cultures it is pointed, "Cultures produce different lives. In short, when cultures are different, communication practices are also different." (Larry A.Samovar, Richard E. Porter and Edwin R.McDanied, 2009:17). Cultural differences, to a great extent, would hinder cultural communication and bring people a lot of inconvenience. Therefore, we must give priority to understanding the culture difference between China and America. With the deepening of reform and opening-up policy, with the help of newspapers, magazines, the Internet, movie and television and other medias, people are increasingly familiar with Western cultures. Among them, films and TV series, as a popular and popular cultural communication, play a very important role in better and deeper understanding Western cultures for Chinese people. Some classical movies and television series are the essence of the typical events and real life experiences.

\section{INTRODUCTION TO THE MOVIE THE GUASHA TREATMENT}

The movie tells a story that happened in the city of Saint Louis, the Mississippi River in the middle part of the United States. Mr. Xu Datong, the hero of film Guasha Treatment, has been living and working as a designer of video games in the United States for 8 years. As a Chinese immigrant, he has become successful, receiving many awards in his career and has a happy family. "I love America, and my American dream has come true," he said excitedly when he won a video game production award at the year-end industry awards conference. But what happened next made his American dream completely broken. His son Denis is sick and Datong's father who cannot read English words and had just come from China, so he performed Guasha on Dennis.In the Chinese culture, Guasha is a traditional therapy that can be a supplement in treating some disease. Then Dennis' head was injured in an accident and he was sent to hospital by Datong immediately. The scratches on Denis's back are 
cindered to be illegal and became evidence of child abuse. So Datong was accused of abusing child. Bad luck falls on such a nice and happy family overnight. Later because of the efforts by Datong, Quinlan, Datong' boss and good friend in lawyer, the family finally reunited after one hardship after another.

\section{TyPiCAl Culture MicRocosm Between China AND AMERICA REFLECTED IN THE MOVIE}

As movie is always closely to the social life of people and we can find what the real life is like in it. Nearly all aspects of life in the human society can be found in the film. Human life is the origin of movies. That is to say in movies, we can always find the image representation of all aspects of social life. The Guasha Treatment as a movie which reflects cultural diversity or differences between China and America. The plots of the movie are full of ups and downs: there are happy and moving moments when Xu Datong's American dream has finally come true and the family shares joy.There is love between parent and the son or love between grandfather and grandson, or the love between husband and wife. But there are also terrible moments when Xu Datong is accused of child abuse by the Child Welfare Agency and Dennis is taken away from his parents. The life of the entire family seems getting into a mess. Datong's father is forced to return China and Denis was sent to the Child Welfare Agency. Datong was not allowed meeting with his son. These movie clips reflect cultural differences and conflicts in China and the United States in some ways. I am going to illustrate three typical cultural differences or diversity reflected in the movie the Guasha Treatment in the following three aspects: kinship ties, laws, and outlook on face and facework.

\section{A. Kinship Ties and Laws}

In the movie clip, to treat his young grandson, Datong's father performs Guasha on Dennis and it works but leaving red scars on his back; To avoid his father being punished, Xu Datong lies at any cost that it was Datong himself not his father who performed Guasha on Dennis; To see his father off at the airport, Datong steals Dennis from the welfare house at risks; To have the family reunion on Christmas Day, again, $\mathrm{Xu}$ Datong takes the risk of being arrested and he climbed through the window from the plum to give his best wishes and warm blessings to Dennis. In the Chinese culture, Datong is a responsible and filial man, so he considers it as his responsibility to shoulder up all the troubles and he lies that he does Guasha to Dennis. A series of moving clips in the movie is a reflection of the traditional Chinese culture: Chinese people attaches great importance to kinship ties.

In American law, however, these are not allowed and $\mathrm{Xu}$ Datong has been against the law. His actions have violated the law, because everything in American social life is based on law. As is known to all, the United States is a country with a legal system. Laws exist in the every aspect of people's lives, and any disputes can be solved by means of law. Because of the scrapping, read scars left on Dennis' back are recognized as child abuse, regardless of Datong's explanation. It is very hard for Americans to understand it, because no textbook in the United States is about Guasha treatment (scrapping). Anyone who is sick should be treated with medicine. The scrapping is not a scientific treatment instead they believe Dennis is abused by someone. No one is willing to testify on it. That is why even in the court the judge said, "This hearing is for the purpose of deterring whether there is sufficient evidence to run court proceedings". Evidence and matter are the focus of American law. It can be illustrated in the following dialogues in the movie.

Judge: If you two would chitchat, we can all go home. Does the defendant have something to add?

\section{Quinlan: No.}

$\mathrm{Xu}$ : Yes, I do. I think you don't understand. Guasha is a traditional Chinese medical treatment, used for nearly all kinds of illnesses. For thousands of years, Chinese medicine has recognized that there're seven Jin and eight Mai. An example, it's like a small stream that run into rivers, and in turn falls into the sea. A person's body has an invisible but very complex system of vital network, just like the computer network. And also the human Qi from Dantian finally goes through Dantian. It's the same principle.

Judge: Your client, what did he say?

$\mathrm{Xu}$ : It's kind of...

Judge: It doesn't mind whether we could understand what you say. Perhaps I should provide another way .What does it say on every Missouri license plate?

\section{$\mathrm{Xu}$ : Show me state.}

Judege: Precisely. Can you get an authoritative medical expert to back your testimony in my plain English that an old country judge can understand?"

There is no doubt that Datong have explained it in a scientific way to defend that Guasha is a traditional Chinese treatment, but he didn't have any authoritative expert to testify. There is no sufficient evidence for him in the matter. So in order to protect the rights of children, Child Welfare Agency is bound to accuse the family of long-term neglect and abuse.

\section{B. Outlook on Face and Facework}

Face theory, face and facework: Face theory is a concrete manifestation of politeness principle, and in different cultures there are different interpretations and understandings of face and facework: As is noted in Communication between Cultures, "The term "face" as a metaphor for the self-image you want to protect to other people. Since it is how you want others to see you, it is a product of social interaction and, as such, can be either lost or gained. Facewok is the construction and communication of face. In other words, facework is the various actions you engage in to acquire face for yourself or give face to someone else"(Larry A.Samovar, Richard E. Porter and Edwin R.McDanied,2009:160).The paper tries to analyze the difference of face theory in Chinese and Western culture through several movie clips of the movie Guasha Treatment. 
A brief introduction to one of the movie clips: Knowing that Denis spanked Quinlan's son, Xu Datong immediately asked his son to apologize to him. Instead of apologizing, Denis spat on him in the presence of Quinlan and his wife. Then, Xu Datong slapped his son. I can be seen from the later movie clip, in order to respect Quinlan, his boss, Datong hit his son. And he thinks all what he has done is to give face to Quinlan and to respect him. But at that time Quinlan cannot understand it while Xu Datong thinks he is giving face to Quinlan, his boss and friend.

"The term "face" refers to a person's social honor or existence of the external aura, and is linked with one's social achievements linked" (Zheng Lihua, 2012:99). The facework in China consists of three levels: the face of moral reputation, the face of social honor and the face of friendship. Among them, the face of social honor involves face loving, face saving, face losing, face maintain, face saving, face giving and son. In the Chinese culture face maintaining is very important. My face is very important and other people's face is also very important. In social interaction, we should not only attempt to maintain each other's face, but also to give each other face and improve their position. Therefore, from the perspective of outlook on face of Chinese culture, Xu Datong's move appears to be well understood by Chinese, the reason he hit Dennis is to respect and give face to Quinlan. In the eyes of the Chinese, the child is his own private property. He has every right to hit his son for the sake of saving his own face and giving face to his friend as Chinese attaches great importance to their face giving in other's presence. In the movie, Xu Datong hit his son and he thinks Quinlan will give him face in return. While in Quinlan's opinion, kid hitting is illegal in the United States no matter whom he is doing on. I think Americans do not understand the Chinese face theory and child rearing. They don't know Chinese parents are heart broken when the hit their loving kids for giving and maintaining face.

In the western culture or American cultures, outlook on face and facework is different, Quinlan can't understand Xu Datong's rude behavior on his kid is to respect and give his face because Americans respect the facts, lay emphasis on equality and focus on children's ability to solve their own problem. In their culture beating and scolding the child is a cruelty to children. Freedom and satisfaction of individual's desire are placed on the first place. They would not sacrifice themselves for saving and giving face to others. They do not like to impose their wishes on others. In the eyes of Westerners, belittle yourself is a benighted behavior, how can you see it as a respect for others.

\section{CONCLUSION}

The movie Guasha Treatment in which three of the typical cultural differences between China and American are shown to audience in the form of film art. As it originates from life and can be higher than life in terms culture. A good film can give us a vivid picture of the current social culture. The movie set us a good example for better intercultural communication and more emphasis on the cultivation of cross-cultural awareness. As there are different values in different cultures, in order to avoid culture conflicts, we have reasons to know about culture diversity and sometimes movies can not only be an effective means of cross-cultural communication but also can provide favorable evidence for cross-cultural studies.

\section{REFERENCES}

[1] Larry A.Samovar, Richard E. Porter \& Edwin R. McDanied, Communications between Cultures, 6th ed., Beijing: Peking University Press, 2009, pp.17-160.

[2] Xu Lisheng, Communications between Cultures, 2nd ed., Shanghai: Shanghai Foreign Language Education Press, 2009, pp.30-40.

[3] Zheng Lihua, Communication and Face Games: An Interactional Sociolinguistic Approach, Shanghai: Shanghai Foreign Language Education Press, 2012, pp.99-100.

[4] Project Team of College English Elective Course, A Multimedia Approach to Intercultural Communication, Beijing: Higher Education Press Language Education Press, 2009, pp.34-45..

[5] Collins Cobuild Advanced Dictionary of English, Beijing: Higher Education Press Language Education Press, 2009, pp.263. 